\title{
Genetic susceptibility to progressive massive fibrosis in coal miners
}

\author{
B. Yucesoy*, V.J. Johnson*, G.E. Kissling\#, K. Fluharty*, M.L. Kashon`, J. Slaven ", \\ D. Germolec ${ }^{+}$, V. Vallyathan ${ }^{\S}$ and M.I. Luster*
}

ABSTRACT: Progressive massive fibrosis (PMF) is a chronic interstitial lung disease with a complex aetiology that can occur after cumulative dust exposure. A case-control study was conducted to test the hypothesis that single nucleotide polymorphisms (SNPS) within genes involved in inflammatory and fibrotic processes modulate the risk of PMF development.

The study population consisted of 648 underground coal miners participating in the National Coal Workers Autopsy Study, of which 304 were diagnosed with PMF. SNPs that influence the regulation of interleukin (IL)-1, IL-6, tumour necrosis factor- $\alpha$, transforming growth factor- $\beta 1$, vascular endothelial growth factor (VEGF), epidermal growth factor intercellular cell adhesion molecule (ICAM)-1 and matrix metalloproteinase-2 genes were determined using a 5'-nuclease real-time PCR assay.

There were no significant differences in the distribution of any individual SNP or haplotype between the PMF and control groups. However, the polygenotype of VEGF $+405 /$ ICAM-1 +241/IL-6 -174 (C-A-G) conferred an increased risk for PMF (odds ratio 3.4, 95\% confidence interval 1.3-8.8).

The present study suggests that the examined genetic variations that help regulate inflammatory and fibrotic processes are unlikely to strongly influence susceptibility to this interstitial lung disease, although the role of vascular endothelial growth factor, intercellular cell adhesion molecule-1 and interleukin-6 polymorphisms in the development of progressive massive fibrosis may require further investigation.

KEYWORDS: Coal miners, cytokines, polymorphism, progressive massive fibrosis

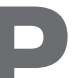
rogressive massive fibrosis (PMF) is a severe form of coal workers' pneumoconiosis (CWP), characterised by bilateral asymmetrical lesions and a background of simple CWP and emphysema. Pathologically, PMF is defined as parenchymal lesions of $\geqslant 2 \mathrm{~cm}$ in diameter, most often found in the upper posterior portions of the lungs. These lesions may obliterate blood vessels and bronchioles and lead to respiratory insufficiency and hypoxia. PMF can develop and progress even after exposure to coal dust has ceased. Progression from simple pneumoconiosis to PMF has been related to the extent and duration of dust exposure, impaired clearance and frequency of pulmonary infections [1].

The pulmonary response following coal dust exposure is characterised by inflammation, epithelial cell injury, proliferation of interstitial cells and the development of coal mine dust-induced pathological lesions with varying amounts of collagen. Cytokines released by activated macrophages are involved in the recruitment of inflammatory cells into the alveolar walls and spaces. These inflammatory mediators also play a role in the remodelling process through stimulation of fibroblast proliferation and collagen synthesis $[2,3]$. Increased levels of tumour necrosis factor (TNF)- $\alpha$, interleukin (IL)-1, IL-6 and intercellular cell adhesion molecule (ICAM)-1 have been found in experimental models of pulmonary fibrosis $[4,5]$ and in the airways of coal miners [6, 7]. Continuous release of TNF- $\alpha$ from alveolar macrophages has been reported in miners with PMF [7]. The measurement of coal dust-induced TNF- $\alpha$ release along with transforming growth factor (TGF)- $\beta$ was proposed as a marker of CWP for the identification of high- and low-risk groups [8].

Growth factors, such as TGF- $\beta$, promote synthesis and deposition of extracellular matrix. Others, such as epidermal growth factor and vascular endothelial growth factor (VEGF), promote proliferation and maturation of epithelial and endothelial cells. TGF- $\beta$ has been widely implicated in the development and progression of experimental and human lung fibrosis $[9,10]$. Increased levels of TGF- $\beta 1$ were found in bronchoalveolar lavage fluid of miners with simple CWP [11] and in the areas of scar tissue
AFFILIATIONS

*Toxicology and Molecular Biology,

"Biostatistics and Epidemiology, and

${ }^{\S}$ Pathology and Physiology Research Branches, Centers for Disease Control and Prevention (CDC)/ National Institute for Occupational Safety and Health (NIOSH),

Morgantown, WV

${ }^{\#}$ Biostatistics, and

+Toxicology Operations Branches, National Institute of Environmental Health Sciences, Research Triangle Park, NC, USA

CORRESPONDENCE

B. Yucesoy, Toxicology and Molecular Biology Branch, Health Effects Laboratory Division, National Institute for Occupational Safety and Health, 1095 Willowdale Road, WV 26505-2888, USA. Fax: 1 3042855708

E-mail: byucesoy@cdc.gov

Received:

June 202007

Accepted after revision:

January 282008

\section{SUPPORT STATEMENT}

This study was supported in part by an Interagency Agreement with the National Institute of Environmental Health Sciences, Division of Intramural Research (Y1-ES-0001)

\section{STATEMENT OF INTEREST}

None declared.

European Respiratory Journal Print ISSN 0903-1936 Online ISSN 1399-3003 
in the silicotic PMF lesions [12]. Pulmonary inactivation of VEGF causes changes that are characteristic of emphysema in mice [13], and reduced pulmonary levels of VEGF are found in patients with emphysema and pulmonary fibrosis [14]. In addition, matrix metalloproteinases have been implicated in the pathogenesis of pulmonary fibrosis due to their roles in tissue repair and remodelling $[15,16]$. Therefore, the early and persistent expression of pro-inflammatory cytokines and subsequent presence of growth factors, cell surface adhesion molecules and fibrogenic factors control the hallmarks of pulmonary fibrosis.

In contrast to other occupational pulmonary diseases, there are limited studies investigating susceptibility genes for PMF. Pulmonary fibrosis is a multifactorial disease likely to be influenced by a number of genetic and environmental factors. Therefore, it is unlikely that any single gene variant would have a major influence on disease risk. It is possible that multiple events act in concert in the development and progression of the disease, as suggested by the fact that only a minority of CWP cases $(0.7 \%)$ progress to PMF [17]. Therefore, in the present study, combinatorial effects of multiple single nucleotide polymorphisms (SNPs) were examined in the genes involved in this complex disease process in a large group of coal workers.

\section{METHODS}

\section{Study population}

The study population consisted of a subgroup of 700 male underground coal miners and demographic information submitted to the National Coal Workers Autopsy Study. From a total of 6,580 autopsy lung tissues received during 1972-1996, 525 cases with histologically confirmed PMF were re-reviewed and graded for CWP and other disease status according to the criteria and schema developed by a joint committee of the College of American Pathologists and the National Institute for Occupational Safety and Health [18]. A total of 175 cases were excluded on the basis of having conglomerate silicosis. The histological criteria used to establish PMF cases included the presence of discrete, highly coal dust-laden fibrotic lesions measuring $>1 \mathrm{~cm}$ with irregular deposition of collagen fibres in a minimum of three lung sections from each case. Lung tissues from 344 coal miners matched for age, smoking history and underground exposure history, but without any histopathological evidence of pulmonary disease, served as controls. The individuals were from different mines but were from similar geographical coal mining areas.

\section{Genotyping}

Genomic DNA was prepared from formalin-fixed, paraffinembedded lung tissue blocks following microwave deparaffinisation using a commercial DNA isolation kit (Promega, Madison, WI, USA). Genotyping was performed on genomic DNA, using a 5'-nuclease PCR assay. Primers and probes were designed using the Assay-by-Design ${ }^{\mathrm{TM}}$ service (Applied Biosystems, Foster City, CA, USA). Table 1 lists the primer and probe sequences for each polymorphism. PCR amplification was performed in a volume of $25 \mu \mathrm{L}$ containing $10 \mathrm{ng}$

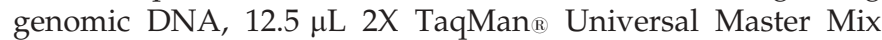
(Applied Biosystems), $200 \mathrm{nM}$ probe and $900 \mathrm{nM}$ primer.
Cycling conditions were $50^{\circ} \mathrm{C}$ for $2 \mathrm{~min}$ and $95^{\circ} \mathrm{C}$ for $10 \mathrm{~min}$, followed by 50 cycles at $92^{\circ} \mathrm{C}$ for $30 \mathrm{~s}$ and $60^{\circ} \mathrm{C}$ for $1 \mathrm{~min}$. Amplification was performed using an iCycler ${ }_{\circledR}$ IQ (Biorad Laboratories, Hercules, CA, USA) real-time thermal cycler. Positive (DNA freshly obtained from human blood samples) and negative controls were included within each run to determine experimental consistency. All samples with ambiguous results were repeated, as were a random selection of $10 \%$ of all samples, to ensure laboratory quality control.

The overall rate of successful DNA isolation was $>90 \%$, which is consistent with other studies that examined fixed tissues [19]. Unsuccessful isolations were slightly more likely to occur in cases than in controls due to the tissue quality in samples with extensive fibrotic lesion and coal dust accumulation.

\section{Statistical analysis}

Differences between PMF cases and controls with respect to demographic and other characteristics of the subjects were evaluated using Chi-squared tests for discrete variables and unpaired two-sample t-tests for continuous variables. Data sets that violated the normality assumption of these analyses were analysed after normalising transformations. There were no significant differences between cases and controls based upon age or smoking history. For reasons of power, heterozygous and homozygous subjects for the risk allele of each SNP were combined into carriers of at least one copy of the risk allele. Potential associations between each SNP and PMF were tested using Chi-squared tests for single SNP associations and Mantel-Haenszel Chi-squared tests for multiple SNP associations. The Breslow-Day test was performed to evaluate homogeneity of the odds ratios (OR). The ExpectationMaximisation algorithm was used to determine haplotypes and their frequencies. A Chi-squared test was performed to determine haplotype-phenotype association by comparison with a reference haplotype chosen on the basis that it was present most frequently.

\section{RESULTS}

The demographic characteristics of the study groups included in the analyses are described in table 2.

Emphysema was present in both PMF and control groups (93.7 and $84.2 \%$, respectively), most likely caused by smoking and focal emphysema associated with macules.

Differences in individual genotype frequencies between cases and controls did not reach statistical significance for any of the individual polymorphisms studied (table 3). As unsuccessful genotyping of subjects did not occur in the same individuals for every gene, each analysis did not have the same sample size. The reported frequencies for each genotype are based on all samples successfully genotyped.

The allele frequencies in the control population were similar to those determined in other studies involving Caucasian populations and were in Hardy-Weinberg equilibrium (data not shown).

Likewise, there were no significant associations detected with disease when interactions among two variants were examined. This apparent lack of association, however, can be misleading if the association between one SNP and disease is dependent upon whether the risk allele for the second SNP is present, 
TABLE 1 Real-time PCR primer and probe sequences

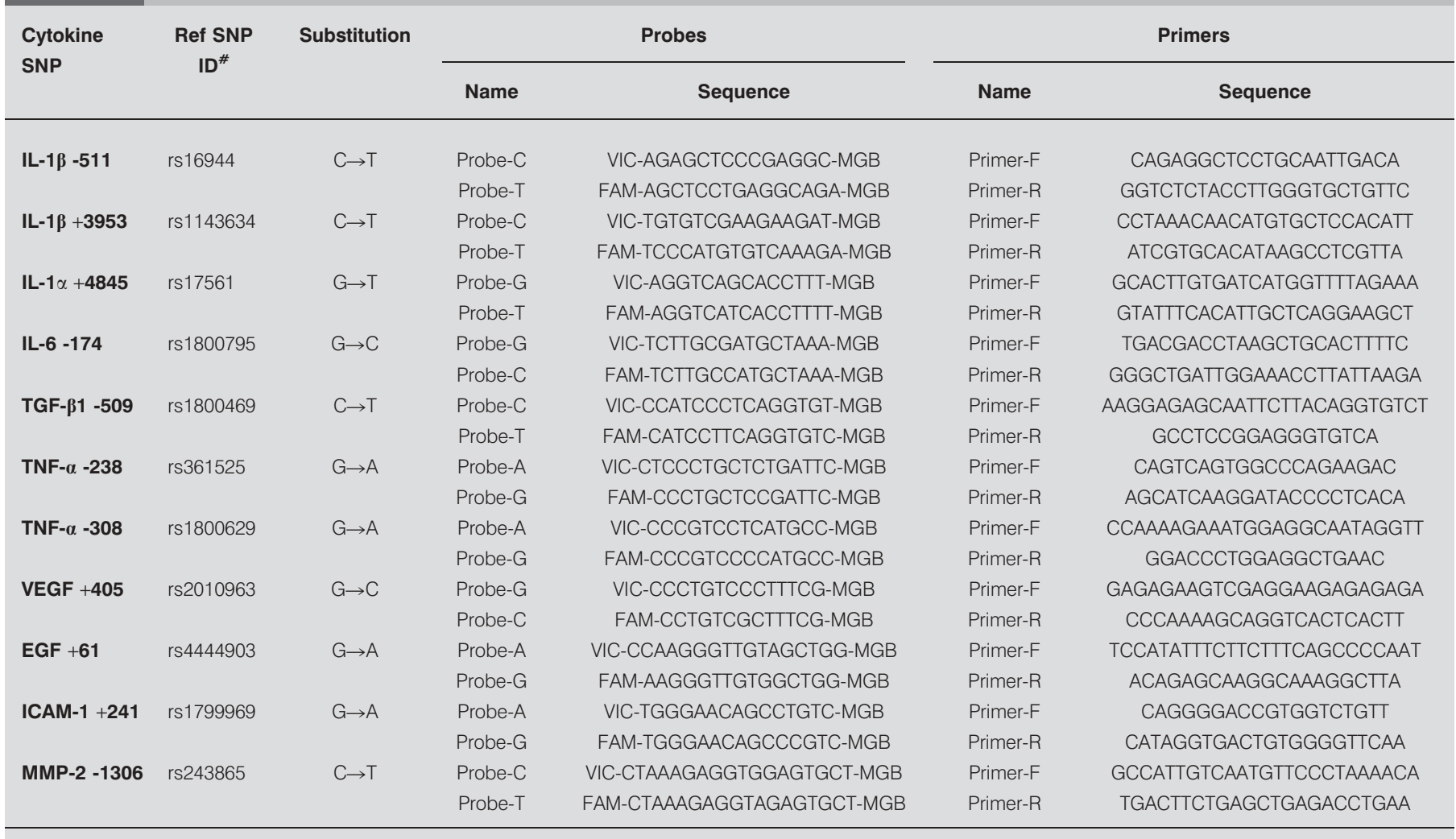

SNP: single nucleotide polymorphism; IL: interleukin; TGF: transforming growth factor; TNF: tumour necrosis factor; VEGF: vascular endothelial growth factor; EGF: epidermal growth factor; ICAM: intercellular cell adhesion molecule; MMP: matrix metalloproteinase; VIC: probe dye; FAM: probe dye; MGB: minor groove binder F: forward; R: reverse. *: National Center for Biotechnology Information reference SNP ID.

i.e. if the ORs are heterogeneous. The ORs were significantly heterogeneous for the VEGF +405/ICAM-1 +241, VEGF +405/ IL-6 -174, and TNF- $\alpha-238 /$ TNF- $\alpha-308$ pairs. Examinations of only these pairs, along with the triple VEGF +405/ICAM-1 +241/IL-6 -174 combination, found no significant association of the TNF- $\alpha-238 /$ TNF- $\alpha-308$ pair with PMF. However, individuals with the combined genotype (polygenotype) of VEGF +405/ICAM-1 +241/IL-6 -174 (C-A-G) were at a significantly higher risk of developing PMF (OR 3.4, 95\% confidence interval 1.3-8.8) than individuals with the other allelic combinations of VEGF, ICAM-1 and IL-6 SNPs. Of the individuals having the polygenotype VEGF +405/ICAM-1 +241/IL-6 -174 (C-A-G), 74\% had PMF and 26\% did not.

Haplotype analysis was performed for the TNF- $\alpha$ and IL-1 genes. Two SNPs in TNF- $\alpha$ and three SNPs in the IL-1 genes generated four and eight haplotypes, respectively. In logistic regression analyses, the reference haplotypes carrying only the most common alleles, TNF- $\alpha-238 /$ TNF- $\alpha-308$ (G-G, 78.38\%) and IL-1 $\beta-511 / \mathrm{IL}-1 \beta+3953 / \mathrm{IL}-1 \alpha+4845$ (C-C-G, 37.64\%), were the reference haplotypes that were to be compared with all other haplotypes. There were no significant differences between the other haplotypes and the reference haplotype in any of the comparisons, with or without any adjustments for the significant covariates. Likelihood estimates for the covariates also indicated that none of the covariates were significant indicators of PMF.

\section{DISCUSSION}

In the present study, the frequency distribution of SNPs in genes involved in the regulation of inflammatory and fibrotic processes was investigated in a population of coal miners with and without PMF. None of the investigated polymorphisms had a statistically significant effect on disease when studied individually or in pairs. The present authors determined that

TABLE 2 Demographic characteristics of the study groups

\begin{tabular}{lccc} 
& Control & PMF & p-value \\
\hline Subjects n & 344 & 304 & \\
Age yrs & $69.9 \pm 9.0$ & $69.9 \pm 8.9$ & 0.97 \\
Smokers \% & 66.5 & 62.4 & 0.56 \\
Smoking yrs & $16.8 \pm 18.2$ & $16.6 \pm 18.8$ & 0.89 \\
Mining yrs & $34.8 \pm 11.4$ & $35.1 \pm 11.2$ & 0.78 \\
Surface yrs & $22.5 \pm 17.1$ & $22.8 \pm 16.7$ & 0.87 \\
Underground yrs & $32.8 \pm 11.8$ & $33.3 \pm 11.6$ & 0.63 \\
Caucasian & $312(91.5)$ & $271(89.4)$ & 0.63 \\
African-American & $16(4.7)$ & $19(6.3)$ & \\
\hline
\end{tabular}

Data are presented as mean \pm SD or $n(\%)$, unless otherwise stated. PMF progressive massive fibrosis. 


\begin{tabular}{|c|c|c|c|}
\hline Genotype & Controls & PMF & OR $(95 \% \mathrm{Cl})$ \\
\hline \multicolumn{4}{|l|}{ TNF- $\alpha-308$} \\
\hline GG & 225 (70.8) & $192(65.8)$ & \\
\hline GA & 83 (26.1) & 85 (29.1) & $1.20(0.84-1.72)$ \\
\hline AA & $10(3.1)$ & $15(5.1)$ & $1.76(0.77-4.00)$ \\
\hline \multicolumn{4}{|l|}{ TNF- $\alpha-238$} \\
\hline GG & 309 (91.4) & 275 (92.0) & \\
\hline GA & 27 (8.0) & $24(8.0)$ & $1.00(0.56-1.77)$ \\
\hline$A A$ & $2(0.6)$ & 0 & \\
\hline \multicolumn{4}{|c|}{ TGF- $\beta 1$-509 } \\
\hline $\mathrm{CC}$ & $170(52.3)$ & $143(50.5)$ & \\
\hline $\mathrm{CT}$ & $121(37.2)$ & 109 (38.5) & $1.07(0.76-1.50)$ \\
\hline$\pi$ & 34 (10.5) & 31 (11.0) & $1.08(0.63-1.85)$ \\
\hline \multicolumn{4}{|l|}{ VEGF +405} \\
\hline GG & $154(47.4)$ & $149(52.0)$ & \\
\hline GC & $130(40.0)$ & $106(36.9)$ & $0.84(0.60-1.18)$ \\
\hline $\mathrm{CC}$ & 41 (12.6) & $32(11.1)$ & $0.81(0.48-1.35)$ \\
\hline \multicolumn{4}{|l|}{$\mathrm{EGF}+61$} \\
\hline GG & $138(44.0)$ & $106(38.0)$ & \\
\hline GA & 132 (41.6) & $121(43.4)$ & $1.19(0.84-1.70)$ \\
\hline AA & $47(14.8)$ & $52(18.6)$ & $1.44(0.90-2.30)$ \\
\hline \multicolumn{4}{|c|}{ ICAM-1 +241 } \\
\hline GG & $245(79.0)$ & $212(78.8)$ & \\
\hline GA & 57 (18.4) & 50 (18.6) & $1.01(0.66-1.54)$ \\
\hline$A A$ & 8 (2.6) & 7 (2.6) & $1.01(0.36-2.83)$ \\
\hline \multicolumn{4}{|l|}{ IL-6 -174 } \\
\hline GG & $122(38.8)$ & $114(42.0)$ & \\
\hline GC & $134(42.7)$ & $113(41.5)$ & $0.90(0.63-1.29)$ \\
\hline $\mathrm{CC}$ & $58(18.5)$ & 45 (16.5) & $0.83(0.52-1.32)$ \\
\hline \multicolumn{4}{|c|}{ MMP-2 -1306 } \\
\hline $\mathrm{CC}$ & 202 (63.3) & $170(61.8)$ & \\
\hline $\mathrm{CT}$ & $97(30.4)$ & $86(31.3)$ & $1.05(0.74-1.50)$ \\
\hline 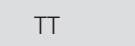 & $20(6.3)$ & $19(6.9)$ & $1.13(0.58-2.18)$ \\
\hline \multicolumn{4}{|l|}{ IL-1 $\alpha+4845$} \\
\hline GG & $179(53.8)$ & $162(55.7)$ & \\
\hline GT & $121(36.3)$ & $104(35.7)$ & $0.95(0.68-1.33)$ \\
\hline$\pi$ & 33 (9.9) & $25(8.6)$ & $0.84(0.48-1.47)$ \\
\hline \multicolumn{4}{|l|}{ IL-1及 -511 } \\
\hline $\mathrm{CC}$ & $136(40.0)$ & 119 (39.3) & \\
\hline СT & $161(47.4)$ & $137(45.2)$ & $0.97(0.69-1.36)$ \\
\hline$\pi$ & 43 (12.6) & 47 (15.5) & $1.25(0.77-2.02)$ \\
\hline \multicolumn{4}{|l|}{ IL-1 $\beta$ +3953 } \\
\hline $\mathrm{CC}$ & 203 (60.6) & $187(63.0)$ & \\
\hline $\mathrm{CT}$ & $110(32.8)$ & $93(31.3)$ & $0.92(0.65-1.29)$ \\
\hline$\pi T$ & $22(6.6)$ & $17(5.7)$ & $0.84(0.43-1.63)$ \\
\hline
\end{tabular}

Data are presented as $n(\%)$, unless otherwise stated. PMF: progressive massive fibrosis; OR: odds ratio; Cl: confidence interval; TNF: tumour necrosis factor; TGF: transforming growth factor; VEGF: vascular endothelial growth factor; EGF: epidermal growth factor; ICAM: intercellular cell adhesion molecule; IL: interleukin; MMP: matrix metalloproteinase.

the study had sufficient statistical power to report this finding. Based on the observed minor allele frequencies among the controls between 21.0 and $61.2 \%$, the study had $90 \%$ power to detect an OR of $\geqslant 1.8$ if it existed. For the rarest minor allele frequency, $8.6 \%$ (i.e. TNF- $\alpha-238$ ), an OR of $\geqslant 2.2$ could be detected with $90 \%$ power.

Since common variants contribute only a small fraction to the overall disease risk, it is not unexpected that the individual SNPs did not reach statistical significance. In a multifactorial disease, such as PMF, it is likely that genetic susceptibility is dependent upon the effect of multiple gene polymorphisms acting at each step in combination with exposure. Although the selection of candidate genes was based on their biological roles in the disease process, it was limited to the genes that have already been identified and characterised. There are potentially many, as yet unidentified, genetic variants that can contribute to PMF risk. Alternatively, disease risk could also depend on polymorphisms in linkage disequilibrium with other variations that influence susceptibility to PMF. Moreover, interindividual differences in the expression of selected genes may influence disease progression by acting as disease modifiers. These variants may modify the progression or severity of disease alone or in certain genotype combinations, in the presence of other genetic or environmental factors. Alternatively, they could represent the modifying effects of genetic factors that have yet to be described. However, the present study design was not appropriate for such evaluation, due to the presence of only severe cases of disease.

Previous association studies in coal miners have focused primarily on investigation of SNPs in the TNF- $\alpha$ and IL-1 genes. It has been shown that the TNF- $\alpha-238$ and -308 variants are associated with silicosis [20, 21]. In a recent study investigating TNF- $\alpha$ gene variations in Japanese miners with CWP and PMF, no association was found between the TNF- $\alpha$ -238 and -308 variants and PMF [22], and it was suggested that these variants may not be related to the severity of CWP. The present results confirm this conclusion in a significantly larger group of coal miners. IL-1 $\beta+3953$ and -511 polymorphisms have also been studied in silicosis, but no associations were found between these variants and disease [23]. Recently, the IL-1 $\alpha-889$ SNP was reported to be associated with CWP susceptibility in a Chinese population [24]. However, the study did not have enough power to detect statistically significant associations, due to its small sample size (45 miners with CWP).

Although none of the individual SNPs selected were associated with PMF, three-way interaction analyses showed that the VEGF +405, ICAM-1 +241 and IL-6 -174 SNPs might interact synergistically to affect the occurrence of PMF. The combinatorial effect of VEGF +405, ICAM-1 +241, and IL-6 -174 gene variants appears to mirror the interaction observed in vivo between VEGF, ICAM- 1 and IL-6 proteins. IL- 6 plays a key role in driving the acute inflammatory response and in the production of acute phase proteins [25]. Although the role of the $-174 \mathrm{G} \rightarrow \mathrm{C}$ SNP in the IL-6 gene in disease is unclear, several studies showed that the $G$ allele was associated with higher plasma levels [26] and with various inflammatory lung diseases [27]. In vivo studies have shown that a reciprocal interaction between IL-6 and ICAM-1 influence production of other acute phase proteins and hence amplifies and maintains the inflammatory response. ICAM- 1 has been shown to play a critical role in bleomycin-induced pulmonary fibrosis by regulating the production of pro-inflammatory cytokines 
including IL-6 [28]. A polymorphism in codon +241 (A allele) was found to be associated with a lower serum ICAM-1 level and chronic inflammatory diseases [29, 30]. IL-6 also plays multiple roles in angiogenesis and vascular remodelling by upregulating VEGF, a major regulator of angiogenesis, in both transcription and protein levels in many cell types [31]. The polymorphism at $+405 \mathrm{G} \rightarrow \mathrm{C}$ has been shown to regulate VEGF expression, and higher production has been associated with the $+405 \mathrm{G}$ allele [32]. Elevated levels of VEGF and soluble ICAM-1 have been linked to elevated IL-6 levels in breast cancer [33]. Under in vitro conditions, VEGF induces the expression of cell adhesion molecules, such as ICAM-1, in endothelial cells and promotes the adhesion of leukocytes [34]. Thus, particular SNPs in the VEGF, ICAM-1 and IL-6 genes may influence the interaction and amplification process between these genes, and play an important role in the pathogenesis of pulmonary fibrosis.

Taken together, the results suggest that the individual single nucleotide polymorphisms are unlikely to have a significant role in the development of progressive massive fibrosis. This is the first extensive genetic study that highlights a possible combinatorial effect of interleukin-6, vascular endothelial growth factor and intercellular cell adhesion molecule-1 functional single nucleotide polymorphisms in progressive massive fibrosis. Since single nucleotide polymorphism interactions provide insight into the relationship of complex pathways and highlight key genes that could be targets for further studies, the polygenotype/disease association found in the present study requires further exploration in independent data sets. Furthermore, it will be important to examine the functional effects of other variant combinations in these genes, to understand the mechanisms by which they modulate susceptibility to progressive massive fibrosis.

\section{ACKNOWLEDGEMENTS}

The authors would like to thank P.A. Willard for excellent technical assistance in the preparation of tissues and M. Rao and F. Chen for their excellent review of the manuscript (all at the Pathology and Physiology Research Branch, CDC/NIOSH, Morgantown, WV, USA). The findings and conclusions in this report are those of the authors and do not necessarily represent the views of the NIOSH.

\section{REFERENCES}

1 Castranova V, Vallyathan V. Silicosis and coal workers' pneumoconiosis. Environ Health Perspect 2000; 108: Suppl. 4, 675-684.

2 Lupher ML Jr, Gallatin WM. Regulation of fibrosis by the immune system. Adv Immunol 2006; 89: 245-288.

3 Ward PA, Hunninghake GW. Lung inflammation and fibrosis. Am J Respir Crit Care Med 1998; 157: S123-S129.

4 Piguet PF, Collart MA, Grau GE, Sappino AP, Vassalli P. Requirement of tumour necrosis factor for development of silica-induced pulmonary fibrosis. Nature 1990; 344: 245-247.

5 Lappalainen U, Whitsett JA, Wert SE, Tichelaar JW, Bry K. Interleukin-1 $\beta$ causes pulmonary inflammation, emphysema, and airway remodeling in the adult murine lung. Am J Respir Cell Mol Biol 2005; 32: 311-318.
6 Lassalle P, Gosset P, Aerts C, et al. Abnormal secretion of interleukin-1 and tumour necrosis factor- $\alpha$ by alveolar macrophages in coal worker's pneumoconiosis: comparison between simple pneumoconiosis and progressive massive fibrosis. Exp Lung Res 1990; 16: 73-80.

7 Vanhée D, Molet S, Gosset P, et al. Expression of leucocyteendothelial adhesion molecules is limited to intercellular adhesion molecule-1 (ICAM-1) in the lung of pneumoconiotic patients: role of tumour necrosis factor- $\alpha$ (TNF- $\alpha$ ). Clin Exp Immunol 1996; 106: 541-548.

8 Borm PJA, Schins RPF. Genotype and phenotype in susceptibility to coal workers' pneumoconiosis. The use of cytokines in perspective. Eur Respir J 2001; 18: Suppl. 32, 127s-133s.

9 Phan SH, Kunkel SL. Lung cytokine production in bleomycin-induced pulmonary fibrosis. Exp Lung Res 1992; 18: 29-43.

10 Vanhée D, Gosset P, Wallaert B, Voisin C, Tonnel AB. Mechanisms of fibrosis in coal workers' pneumoconiosis. Increased production of platelet-derived growth factor, insulin-like growth factor type I, and transforming growth factor- $\beta$ and relationship to disease severity. Am J Respir Crit Care Med 1994; 150: 1049-1055.

11 Vallyathan V, Goins M, Lapp LN, et al. Changes in bronchoalveolar lavage indices associated with radiographic classification in coal miners. Am J Respir Crit Care Med 2000; 162: 958-965.

12 Jagirdar J, Begin R, Dufresne A, Goswami S, Lee TC, Rom WN. Transforming growth factor- $\beta$ (TGF- $\beta)$ in silicosis. Am J Respir Crit Care Med 1996; 154: 1076-1081.

13 Tang K, Rossiter HB, Wagner PD, Breen EC. Lung-targeted VEGF inactivation leads to an emphysema phenotype in mice. J Appl Physiol 2004; 97: 1559-1566.

14 Koyama S, Sato E, Haniuda M, Numanami H, Nagai S, Izumi T. Decreased level of vascular endothelial growth factor in bronchoalveolar lavage fluid of normal smokers and patients with pulmonary fibrosis. Am J Respir Crit Care Med 2002; 166: 382-385.

15 Swiderski RE, Dencoff JE, Floerchinger CS, Shapiro SD, Hunninghake GW. Differential expression of extracellular matrix remodeling genes in a murine model of bleomycininduced pulmonary fibrosis. Am J Pathol 1998; 152: 821-828.

16 Henry MT, McMahon K, Mackarel AJ, et al. Matrix metalloproteinases and tissue inhibitor of metalloproteinase1 in sarcoidosis and IPF. Eur Respir J 2002; 20: 1220-1227.

17 Attfield MD. British data on coal miners' pneumoconiosis and relevance to US conditions. Am J Public Health 1992; 82: 978-983.

18 Kleinerman JGF, Laqueur W. Pathology standards for coal workers' pneumoconiosis. Pathol Lab Med 1979; 103: 375-431.

19 Gioia L, Vogt LJ, Freeman WM, Flood A, Vogt BA, Vrana KE. PCR-based apolipoprotein E genotype analysis from archival fixed brain. J Neurosci Methods 1998; 80: 209-214.

20 Yucesoy B, Vallyathan V, Landsittel DP, et al. Association of tumor necrosis factor- $\alpha$ and interleukin-1 gene polymorphisms with silicosis. Toxicol Appl Pharmacol 2001; 172: 75-82.

21 Corbett EL, Mozzato-Chamay N, Butterworth AE, et al. Polymorphisms in the tumor necrosis factor- $\alpha$ gene 
promoter may predispose to severe silicosis in black South African miners. Am J Respir Crit Care Med 2002; 165: 690-693.

22 Wang XT, Ohtsuka Y, Kimura K, et al. Antithetical effect of tumor necrosis factor- $\alpha$ gene polymorphism on coal workers' pneumoconiosis (CWP). Am J Ind Med 2005; 48: 24-29.

23 Yucesoy B, Vallyathan V, Landsittel DP, et al. Polymorphisms of the IL-1 gene complex in coal miners with silicosis. Am J Ind Med 2001; 39: 286-291.

24 Fan XY, Yan ZF, Yan JD, Zhang SJ, Bai YP, Yao SQ. [Relationship between polymorphism of interleukin-1 and pneumoconiosis susceptibility.] Zhonghua Lao Dong Wei Sheng Zhi Ye Bing Za Zhi 2006; 24: 526-530.

25 Heinrich PC, Castell JV, Andus T. Interleukin-6 and the acute phase response. Biochem J 1990; 265: 621-636.

26 Fishman D, Faulds G, Jeffery R, et al. The effect of novel polymorphisms in the interleukin-6 (IL-6) gene on IL-6 transcription and plasma IL-6 levels, and an association with systemic-onset juvenile chronic arthritis. J Clin Invest 1998; 102: 1369-1376.

27 Grutters JC, Sato H, Pantelidis P, et al. Analysis of IL6 and IL1A gene polymorphisms in UK and Dutch patients with sarcoidosis. Sarcoidosis Vasc Diffuse Lung Dis 2003; 20: 20-27.

28 Hamaguchi Y, Nishizawa Y, Yasui M, et al. Intercellular adhesion molecule-1 and L-selectin regulate bleomycininduced lung fibrosis. Am J Pathol 2002; 161: 1607-1618.
29 Ponthieux A, Lambert D, Herbeth B, Droesch S, Pfister M, Visvikis S. Association between Gly241Arg ICAM-1 gene polymorphism and serum sICAM-1 concentration in the Stanislas cohort. Eur J Hum Genet 2003; 11: 679-686.

30 Macchioni P, Boiardi L, Casali B, Nicoli D, Farnetti E, Salvarani C. Intercellular adhesion molecule 1 (ICAM-1) gene polymorphisms in Italian patients with rheumatoid arthritis. Clin Exp Rheumatol 2000; 18: 553-558.

31 Cohen T, Nahari D, Cerem LW, Neufeld G, Levi BZ. Interleukin 6 induces the expression of vascular endothelial growth factor. J Biol Chem 1996; 271: 736-741.

32 Holt RC, Ralph SA, Webb NJ, et al. Steroid-sensitive nephrotic syndrome and vascular endothelial growth factor gene polymorphisms. Eur J Immunogenet 2003; 30: 1-3.

33 Hutchins D, Steel CM. Regulation of ICAM-1 (CD54) expression in human breast cancer cell lines by interleukin 6 and fibroblast-derived factors. Int J Cancer 1994; 58: 80-84.

34 Kim I, Moon SO, Kim SH, Kim HJ, Koh YS, Koh GY. Vascular endothelial growth factor expression of intercellular adhesion molecule 1 (ICAM-1), vascular cell adhesion molecule 1 (VCAM-1), and E-selectin through nuclear factor- $\mathrm{\kappa B}$ activation in endothelial cells. J Biol Chem 2001; 276: 7614-7620. 